\title{
The role of nitric oxide on the responses of curcumin-treated rat aorta
}

\author{
Nurullahoglu-Atalik $\mathrm{KE}^{1}$, Gokbel $\mathrm{H}^{2}, \mathrm{Oz} \mathrm{M}^{2}$, Okudan $\mathrm{N}^{2}$, Belviranli $\mathrm{M}^{2}$, Esen $\mathrm{H}^{3}$ \\ Department of Pharmacology, Meram Faculty of Medicine, Necmettin Erbakan University, Konya, Turkey. \\ esraatalik@hotmail.com
}

\begin{abstract}
Objectives: The aim of the present study was to evaluate the influence of endothelial nitric oxide (NO) on the vascular responses of curcumin-treated rats.

Methods: The experimental groups included the control and curcumin-treated ( $200 \mathrm{mg} / \mathrm{kg} /$ day, p.o., for 4 weeks) group. The concentration response curves to receptor-dependent agent 5-hydroxytryptamine $\left(5-\mathrm{HT} ; 10^{-9}-3 \times 10^{-4}\right.$ $\mathrm{M})$ and receptor-independent agent potassium chloride $(\mathrm{KCl} ; 5-100 \mathrm{mM})$ were observed.

Results: The concentration response curves to $5-\mathrm{HT}$ and $\mathrm{KCl}$ shifted to the right and the maximal response was significantly decreased in the curcumin-treated rat aortas. A pretreatment of rings with L-NAME (a NOS inhibitor, $10^{-4} \mathrm{M}$ ) increased both the sensitivity and maximal response to only $5-\mathrm{HT}$. No apparent histological changes were demonstrated in smooth muscle and connective tissue layers in the aortas of the control and curcumin-treated rat preparations.

Conclusion: The results of the present study suggest that NO release from endothelial cells modulates curcumin-treated rat aorta responses to 5- $\mathrm{HT}$, but not to $\mathrm{KCl}$ (Tab. 2, Fig. 4, Ref. 25). Full Text in PDF www.elis.sk. Key words: aorta, curcumine, contractions, serotonin, $\mathrm{KCl}$, nitric oxide.
\end{abstract}

Curcumin is a naturally occurring phenolic compound isolated as a yellow pigment from turmeric (dry rhizomes of curcuma longa), which is commonly used as a spice and food colorant (1). Recently, there has been an increased clinical interest in curcumin. This compound has been reported to posses a variety of biological and pharmacological activities, including antioxidative (2-4), anti-inflammatory (5) anticarcinogenic $(6,7)$ and antidiabetic (8). In addition, curcumin acts as an antioxidant at low doses and prooxidant at high doses (9). Both anti-inflammatory and anti-proliferative activities of curcumin have been shown to be mediated through the prooxidant mechanism (10). In addition to its inherent ability to attenuate the reactivity of oxygen free radical species, curcumin has been shown in vivo to enhance the activities of detoxifying enzymes such as glutathione-Stransferase (11). Since it is widely accepted that oxidative stress and inflammation contribute to atherogenesis, the effects of curcumin on cardiovascular system have also received much attention recently.

Endothelium-derived nitric oxide (NO), synthesized by endothelial NO synthase (eNOS), has several physiological effects, including controlling vascular tone, modulating smooth muscle cell proliferation, and inhibiting platelet aggregation and leukocyte adhesion $(12,13)$. It has been demonstrated that a blockade of NO formation with L-NAME causes an impairment of vascular

Departments of ${ }^{1}$ Pharmacology, ${ }^{3}$ Physiology and ${ }^{4}$ Pathology, Meram Faculty of Medicine, Necmettin Erbakan University, Konya, and ${ }^{2}$ Department of Physiology, Selcuklu Faculty of Medicine, Konya, Turkey

Address for correspondence: K. Esra Atalik, Dept of Pharmacology, Faculty of Meram Medicine, University of Necmettin Erbakan, Konya, 42080, Turkey.

Fax: +90.332 .2237124$ function (14). More recently, curcumin addition to organ bath has been reported to ameliorate a high glucose-induced acute vascular endothelial dysfunction in rat thoracic aorta (15). In this study, we decided to evaluate whether curcumin-treatment influences the effect of NO on vascular responses.

\section{Methods}

Rats

Male Wistar rats (6-8 weeks) were divided randomly into the two groups of six rats each. All experiments were carried out with the approval of Local Animal Use Ethical Committee of Selçuk University. The experimental groups included control and curcumin-treated (200 mg/kg/day, p.o. for 4 weeks). Control rats were injected with saline only. Body weights of rats were measured in all groups before and for 4 weeks after curcumin induction. All rats were kept under identical conditions for 4 weeks with free access to food and tap water before the experiments were conducted.

The descending thoracic aorta was quickly isolated, cleaned and sectioned into 3 to $4 \mathrm{~mm}$ long rings. The rings were then placed in organ baths containing Krebs-Henseleit solution (KHS, $\mathrm{mM}: \mathrm{NaCl} 119, \mathrm{KCl} 4.70, \mathrm{MgSO}_{4} 1.50, \mathrm{KH}_{2} \mathrm{PO}_{4} 1.20, \mathrm{CaCl}_{2} 2.50$, $\mathrm{NaHCO}_{3} 25$, Glucose 11), which was thermoregulated at $37^{\circ} \mathrm{C}$ and aerated $\left(95 \% \mathrm{O}_{2}\right.$ and $\left.5 \% \mathrm{CO}_{2}\right)$. The changes in isometric tension were recorded by a force-displacement transducer (BIOPAC MP36, Santa Barbara, California, USA) connected through amplifiers to a ITBS08 Integrated Tissue Bath System (Commat, Ankara, Turkey). Starting from each aorta, a single ring was prepared for in vitro investigation and sent for pathological research. 


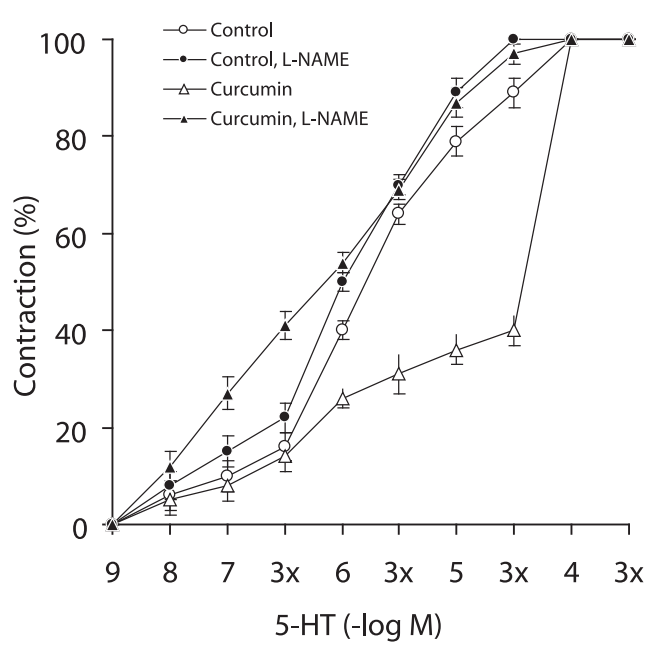

Fig. 1. 5-HT concentration-response curves of aortas from control rats, curcumin-treated rats and curcumin-treated rats in the presence of L-NAME. Each point is the mean \pm SEM of six experiments.

\section{Organ baths}

The rings were equilibrated for 60 min under a resting tension of $1 \mathrm{~g}$ before the experiments began. After equilibration, at the beginning of the experiments, endothelial cell integrity was assessed when a single addition of $\mathrm{ACh}\left(10^{-6} \mathrm{M}\right)$ caused relaxation of aortic segments precontracted with 5-HT. Then the preparations were washed and after equilibration, cumulative concentrationresponse curves to 5 -HT $\left(10^{-9}-3 \times 10^{-4} \mathrm{M}\right)$ and $\mathrm{KCl}(5-100 \mathrm{mM})$ were obtained. Only one agent was tested in each preparation $(n=6)$ from two different rat groups.

The influence of nitric oxide on constrictor responses to 5-HT and $\mathrm{KCl}$ was specifically addressed by pretreating the rings with the nitric oxide synthase inhibitor $\mathrm{N}^{\mathrm{G}}$-nitro-L-arginine methyl ester (L-NAME; $\left.10^{-4} \mathrm{M}\right)$. L-NAME was added to the organ bath 20 min before the concentration-response curves were started. Endothelium did not denude because only the role of endothelial nitric oxide was examined in this study.

\section{Histology}

After formaldehyde fixation, the entire thoracic aorta was sectioned at 6 segments $4 \mathrm{~mm}$ in length. Tissues were embedded in paraffin and Hematoksilen\&Eosin stain was performed on the 4 to $6 \mu \mathrm{m}$ cross-sections of the aorta. Morphometric measurements on all six segments of thoracic aorta were performed by using the Image Analysis System (BAB Bs200ProP Image Processing and Analysis System, Turkey, Ankara), by a pathologist. The luminal

Tab. 1. EC50 values for $\mathrm{PHE}$ and $\mathrm{KCl}$, from control, curcumin-treated, and curcumin-treated+L-NAME rat aorta.

\begin{tabular}{lcc}
\hline & \multicolumn{2}{c}{$\mathrm{EC}_{50}$} \\
\cline { 2 - 3 } Control & 5 -HT $\left(\times 10^{-6} \mathrm{M}\right)$ & $\mathrm{KCl}\left(\mathrm{x} 10^{-2} \mathrm{M}\right)$ \\
\cline { 2 - 3 } Curcumin-treated & $1.7 \pm 0.3$ & $2.2 \pm 0.1$ \\
Curcumin-treated+L-NAME & $40.3 \pm 2.3^{*}$ & $3.1 \pm 0.2^{*}$ \\
\hline
\end{tabular}

Each value is derived from six experiments. Data are given as mean \pm SEM. $* \mathrm{p}<0.05$ compared with control values, $* * \mathrm{p}<0.05$ compared with curcumin-treated values.
Tab. 2. Emax values for 5-HT and KCl, from control, curcumin-treated, and curcumin-treated+L-NAME rat aorta.

\begin{tabular}{lcc}
\hline & \multicolumn{2}{c}{$\mathrm{E}_{\max }(\mathrm{g})$} \\
\cline { 2 - 3 } & $5-\mathrm{HT}$ & $\mathrm{KCl}$ \\
\hline Control & $1.7 \pm 0.1$ & $2.8 \pm 0.1$ \\
Curcumin-treated & $1.1 \pm 0.1^{*}$ & $1.6 \pm 0.2^{*}$ \\
Curcumin-treated+L-NAME & $1.4 \pm 0.1^{* *}$ & $1.7 \pm 0.1$ \\
\hline Each value is derived from six experiments. Data are given as mean $\pm \mathrm{SEM} .{ }^{*} \mathrm{p}<0.05$
\end{tabular}

compared with control values, $* * \mathrm{p}<0.05$ compared with curcumin-treated values.

area was calculated from the perimeter of the luminal border. The luminal area for each thoracic aorta was obtained by averaging these measurements. The mean $\pm \mathrm{SE}$ value obtained from each artery was used as the final value for a particular vessel.

\section{Statistical analysis}

The concentrations of the contractile agents causing $50 \%$ of the maximal response $\left(\mathrm{EC}_{50}\right)$ and maximal responses $\left(\mathrm{E}_{\max }\right)$ for curves were obtained from the four groups. The $\mathrm{EC}_{50}$ and $\mathrm{E}_{\max }$ values were compared by using the Student's $t$-tests. The statistical significance was set at $\mathrm{p}<0.05$.

\section{Chemicals and data analysis}

All chemicals used in experiments were obtained from the Sigma Chemical (St. Louis, MO, USA).

\section{Results}

\section{General characteristics of the rats}

The initial and final body weights for all animals were observed (in the control group 297.5 \pm 5.4 and $327.4 \pm 4.3$, and in the curcumin-treated group $297.1 \pm 5.2$ and $328.4 \pm 6.2$, respectively). There was no difference in the starting weights in the animals. Curcumin treatment did not significantly affect the final weight. 5-HT-induced contraction

5-hydroxytryptamine $\left(10^{-9}-3 \times 10^{-4} \mathrm{M}\right)$ induced the concentration-dependent contractions in the rat aortic rings (Fig. 1). The concentration response curve to 5-HT was shifted to the right and the maximal response was significantly decreased in the curcumin-treated rat aortas. The pretreatment of rings with L-NAME (a NOS inhibitor, $10^{-4} \mathrm{M}$ ) increased both the sensitivity and maximal response to 5-HT (Fig. 1, Tabs 1 and 2).

\section{KCl-induced contraction}

$\mathrm{KCl}(5-100 \mathrm{mM})$ induced the concentration-dependent contractions in the rat aortic rings (Fig. 2). The concentration response curve to $\mathrm{KCl}$ was shifted to the right and the maximal response was significantly decreased in the curcumin-treated rat aortas. Neither the sensitivity nor the maximal response was affected by the pretreatment of rings with L-NAME $\left(10^{-4} \mathrm{M}\right)$.

\section{Histologic examination}

The mean values for the measurements of aortic luminal area were analysed statistically. The average luminal areas of rat aorta were found to be $1210196.7 \pm 0.0623 \mu \mathrm{m}^{2}$ in the control group $(\mathrm{n}=6)$ and $1141573.2 \pm 0.0333 \mu \mathrm{m}^{2}$ in the curcumin-treated group $(n=6)$. There was no statistical differences between these values. No apparent histological changes were demonstrated in smooth 


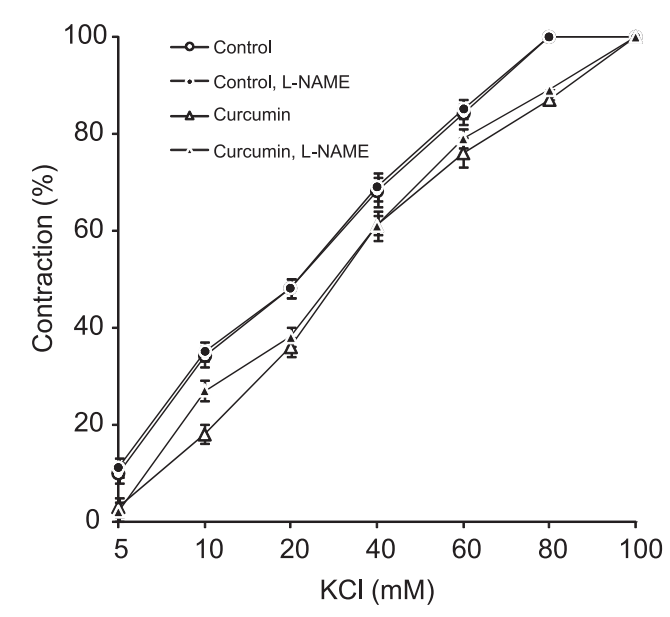

Fig. 2. KCl concentration-response curves of aortas from control rats, curcumin-treated rats and curcumin-treated rats in the presence of L-NAME. Each point is the mean \pm SEM of six experiments.

muscle and connective tissue layers in the aortas of the control and curcumin-treated rat preparations (Figs 3 and 4).

\section{Discussion}

In the present work, we studied the effects of nitric oxide on curcumin $(200 \mathrm{mg} / \mathrm{kg})$, an antioxidant (16-18), treated rat thoracic aorta responses. This dose $(200 \mathrm{mg} / \mathrm{kg})$ of curcumin was previously reported to be a good antioxidant (19). Our study is the first to show the vasoconstrictor responses in aortic rings from curcumintreated rats paying a special attention to the role of nitric oxide.

The present study demonstrates that both 5-HT and $\mathrm{KCl}$ induced the concentration-dependent contractions in rat thoracic aorta. Compared to the control responses, there is a decrease in sensitivity to both 5-HT and $\mathrm{KCl}$ of the endothelium-intact thoracic aortic rings obtained from the curcumin treated rats. With our data we can not suggest, which mechanisms underlied the decreased sensitivity to 5 -HT and $\mathrm{KCl}$ in the curcumin-treated rats. Our results are in agreement with those reported by Morello et al. (20) who have reported that the antioxidant and radical scavenger galangin incubation in rat thoracic aorta reduced the contractility to both phenylephrine and $\mathrm{KCl}$. As we know, 5-HT plays a vasoconstrictor role and increases the vascular resistance in rat aorta (21), producing contractions by calcium influx from extracellular medium through receptordependent calcium channels and calcium release from intracellular stores. $\mathrm{KCl}$ is a receptor independent contractile agent that can stimulate $\mathrm{Ca}^{2+}$ influx through the voltage-sensitive $\mathrm{Ca}^{2+}$ channels. The effect of the curcumin treatment on vascular tone and reactivity has not been studied much. Although Srivastava et al (21) reported that $\mathrm{KCl}$-induced contractions remained unaltered in the presence of free radical scavengers while 5-HT-induced contractions were attenuated. In this study, the similar findings were observed with two different contractile agents. Majithiya and Balaraman (22) reported that chronic curcumin $(200 \mathrm{mg} / \mathrm{kg})$ treatment caused no significant change in the phenylephrine-induced contraction in curcumin-treated rat aorta as compared to the control group. However,

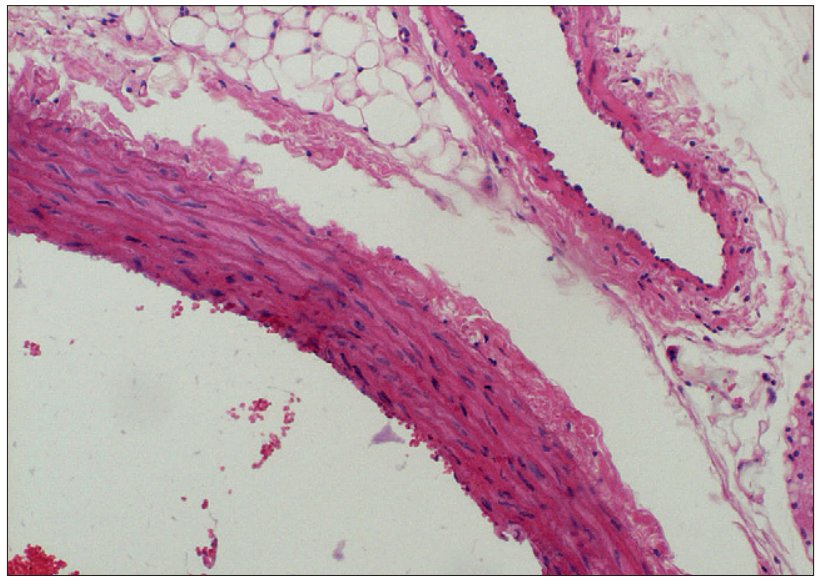

Fig. 3.

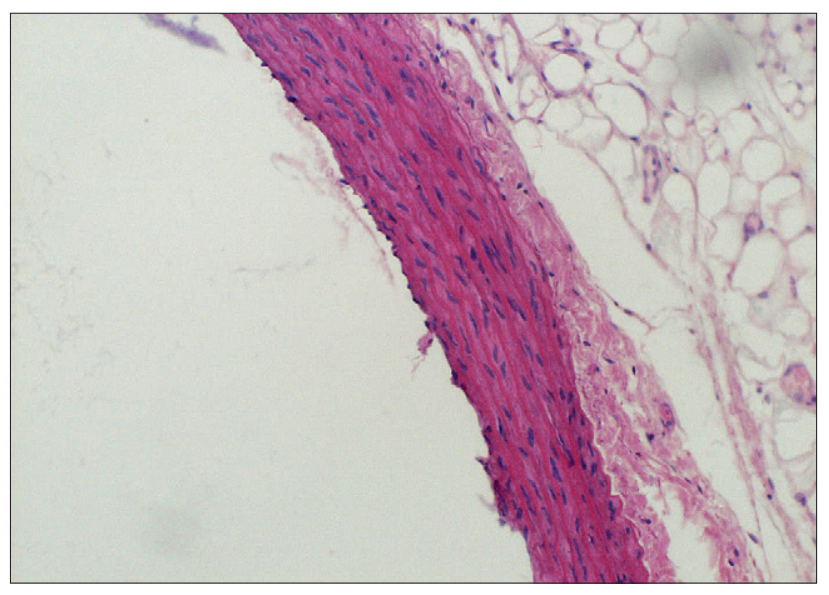

Fig. 4.

the mechanism underlying the effect of curcumin treatment is not clear. The discrepancy between this and our findings might be due to the differences in the agonists or the design of the experiments.

It is well known that nitric oxide (NO) is one of the most important regulators of vascular tone and possesses a variety of important physiological functions in the cardiovascular tone, such as keeping the vessels patent via vasodilation, prevention of platelet aggregation, and regulating the force and rate of contraction (23). In this study, an incubation with L-NAME (NO synthase inhibitor) inhibited the effect of curcumin supplementation in only 5-HT contractions but not in KCl. Similarly, Srivastava et al. (21) reported that the pretreatment of rat aortic rings with free radical scavengers as superoxide dismutase attenuated the 5-HT-induced contractions and the inhibitory effect was significantly reduced in the L-NAMEpretreated rings. The investigators also suggested that the endogenous generation of the reactive oxygen species (ROS) seems to modulate rat aortic ring contractions and the inhibitory effect of the hydroxyl radical scavenger was lower in the L-NAME-pretreated rings. These findings support our observation. Furthermore, Nakmareong et al. (24) demonstrated that the treatment with curcumin restores the eNOS protein expression and resumes its counter bal- 
ance effect with ROS in rats. The investigators also reported the ability of curcumin to increase the NO production and to suppress oxidant formation, thereby increasing NO bioavailability to a level sufficient to maintain "normal" vascular function. In addition, other reports showed that endothelial NO interacts with the ROS generated during rat aortic contractions to norepinephrine (25).

It is unclear whether the reactivity of smooth muscle to $\mathrm{KCl}$ is altered from NO in studies with antioxidants, as there are conflicting reports about the contractile responses in the presence of L-NAME or endothelium-denudation. For example, Morello et al (20) reported that NO release from endothelial cells is partly involved and modulates contraction induced by phenylephrine, but not by $\mathrm{KCl}$, as in our study. These contradictory results indicate that the influence of endothelium removal or L-NAME-incubation seem to depend on both the tissue and the agonist. In this study, we investigated the effect of NO but not the endothelium.

In our study, chronic curcumin supplementation did not affect the luminal area of the rat aorta. Furthermore, no apparent histological changes were demonstrated in smooth muscle and connective tissue layers in the aortas of control and curcumin-treated rat preparations. This finding suggests that curcumin affects aortic smooth muscle response to contractile agents without the effect on vascular structure.

In conclusion, the results from the present study suggest that the basal production of NO by the endothelium seems to affect the vascular contraction induced by $5-\mathrm{HT}$, but not by $\mathrm{KCl}$ due to its interaction with the ROS mediators.

\section{References}

1. Buescher R, Yang L. Turmeric. In: Lauro GJ, Francis FJ (Eds). Natural Food Colorants, Marcel Dekker, New York, 2000, pp. 205-226.

2. Priyadarsini KI, Maity DK, Naik GH et al. Role of phenolic O-H and methylene hydrogen on the free radical reactions and antioxidant activity of curcumin. Free Radic Biol Med 2003; 35 (5): 475-484.

3. Rukkumani R, Sri Balasubashini M, Menon VP. Protective effects of curcumin and photo-irradiated curcumin on circulatory lipids and lipid peroxidation products in alcohol and polyunsaturated fatty acid-induced toxicity. Phytother Res 2003; 17 (8): 925-929.

4. Daniel S, Limson JL, Dairam A et al. Through metal binding, curcumin protects against lead-and cadmium-induced lipid peroxidation in rat brain homogenates and against lead-induced tissue damage in rat brain. J Inorg Biochem 2004; 98 (2): 266-278.

5. Chainani-Wu N. Safety and anti-inflammatory activity of curcumin: a component of turmeric (curcuma longa). J Altern Complement Med 2003; 9 (1): 161-168.

6. Shukla Y, Aroro A, Taneja P. Antimutagenic potential of curcumin on chromosomal berrations in Wistar rats. Mutat Res 2002; 515 (1-2): 197-202.

7. Aqqarwal BB, Kumar A, Bharti AC. Anticancer potential of curcumin: preclinical and clinical studies. Anticancer Res 2003; 23 (1A): 363-398.

8. Srinivasan A, Menon VP, Periaswamy V et al. Protection of pancreatic beta cell by the potential antioxidant bis-hydroxycinnamoyl methane, analogue of natural curcuminoid in experimental diabetes. J Pharm Pharmaceut Sci 2003; 6 (3): 327-333.
9. Sandur SK, Ichikawa H, Pandey MK et al. Role of pro-oxidants and antioxidants in the anti-inflammatory and apoptotic effects of curcumin (diferuloylmethane). Free Radic Biol Med 2007; 43 (4): 568-580.

10. Sandur SK, Pandey MK, Sung B et al. Curcumin, demethoxycurcumin, bisdemethoxycurcumin, tetrahydrocurcumin and turmerones differentially regulate anti-inflammatory and anti-proliferative responses through a ROS-independent mechanism. Carcinogenesis 2007; 28 (8): 1765-1773.

11. Piper JT, Singhal SS, Salameh MS et al. Mechanisms of anticarcinogenic properties of curcumin: the effect of curcumin on glutathione linked detoxification enzymes in rat liver. Int J Biochem 1998; 30 (4): 445-456.

12. Moncada S, Higgs EA. Endogenous nitric oxide; physiology, pathology and clinical relevance. Eur J Clin Invest 1991; 21 (4): 361-374.

13. Bredt DS, Snyder SH. Nitric oxide: a physiologic messenger molecule. Annu Rev Biochem 1994; 63: 175-195.

14. Henrion D, Dowell FJ, Levy BI, Michel JB. In vitro alteration of aortic vascular reactivity in hypertension induced by chronic $\mathrm{N}^{\mathrm{G}}$-nitro-Larginine methyl ester. Hypertension 1996; 28 (3): 361-366.

15. Fang XD, Yang F, Zhu L, et al. Curcumin ameliorates high glucoseinduced acute vascular endothelial dysfunction in rat thoracic aorta. Clin Exp Pharmacol Physiol 2009; 36 (12): 1177-1182.

16. Motterlini R, Foresti R, Bassi R, Green GJ. Curcumin, an antioxidant and anti-inflammatory agent, induces heme oxygenase-12 and protects endothelial cells against oxidative stress. Free Radic Biol Med 2000; 28 (8): 1303-1312.

17. Biswas SK, McClure D, Jimenez LA et al. Curcumin induces glutathione biosynthesis and inhibits NF-kappaB activation and interleukin-8 release in alveolar epithelial cells. Mechanism of free radical scavenging activity. Antioxid Redox Signal 2005; 7 (1-2): 32-41.

18. Farombi EO, Abarikwu SO, Adedara IA, Oyeyemi MO. Curcumin and kolaviron ameliorate di- n-butylphthalate-induced testicular damage in rats. Basic Clin Pharmacol Toxicol 2007; 100 (1): 43-48.

19. Sajithlal GB, Chithra P, Chandrakasan G. Effect of curcumin on the advanced glycation and cross-linking of collagen in diabetic rats. Biochem Pharmacol 1998; 56 (12): 1607-1614.

20. Morello S, Vellecco V, Alfieri A, et al. Vasorelaxant effect of the flavanoid galangin on isolated rat thoracic aorta. Life Sci 2006; 78 (8): 825-830.

21. Srivastava P, Rajanikanth SA, Raghavan SAV, Dikshit M. Role of endogenous reactive oxygen derived species and cyclooxygenase mediators in 5-hydroxytryptamine-induced contractions in rat aorta: relationship to nitric oxide. Pharmacol Res 2002; 45 (5): 375-382.

22. Nakmareong S, Kukongviriyapan U, Pakdeechote P, etal. Antioxidant and vascular protective effects of curcumin and tetrahydrocurcumin in rats with L-NAME-induced hypertension. Naunyn Schmiedebergs Arch Pharmacol. 2011; 383 (5): 519-529.

23. Majithiya JB, Balaraman R. Time-dependent changes in antioxidant enzymes and vascular reactivity of aorta in streptozotocin-induced diabetic rats treated with curcumin. J Cardiovasc Pharmacol 2005; 46 (5): 697-705.

24. Alderton WK, Cooper CE, Knowles RG. Nitric oxide synthases: structure, function and inhibition. Biochem J 2001; 357 (3): 593-615.

25. Srivastava P, Hegde LG, Patnaik GK, Dikshit M. Role of endothelial-derived reactive oxygen species and nitric oxide in norepinephrineinduced rat aortic ring contractions. Pharmacol Res 1998; 38 (4): 265-274.

Received September 15, 2011. Accepted October 11, 2011. 